\title{
Erratum to: Evaluation of Three Multiresidue Methods for the Determination of Pesticides in Marijuana (Cannabis sativa L.) with Liquid Chromatography-Tandem Mass Spectrometry
}

\author{
Andrés Pérez-Parada $^{1}$ Beatriz Alonso ${ }^{1}$ Cintia Rodríguez ${ }^{1}$ Natalia Besil ${ }^{1,2}$. \\ Verónica Cesio $^{1} \cdot$ Laura Diana $^{1} \cdot$ Anna Burgueño $^{1} \cdot$ Paula Bazzurro $^{1}$. \\ Alejandra Bojorge ${ }^{1} \cdot$ Natalia Gerez $^{1} \cdot$ Horacio Heinzen ${ }^{1,2}$
}

Published online: 29 June 2016

(C) Springer-Verlag Berlin Heidelberg 2016

\section{Erratum to: Chromatographia \\ DOI 10.1007/s10337-016-3029-9}

The first reference was incorrect in the original version of the article. The corrected version is as shown below.

Cannabis sativa L. might just be the most famous plant species on the planet, since humans have been using it as such or some of its products since 5000 years or more for different purposes [1,2].

\section{References}

1. Zwenger SR (2014) The biotechnology of Cannabis sativa, 2nd edn. Extreme Publications Inc., p 265

2. Clarke RC, Merlin MD (2013) Cannabis: evolution and ethnobotany. University of California Press, p 464

Published in the topical collection 5th Latin American Pesticide Residue Workshop with guest editor Steven J. Lehotay.

The online version of the original article can be found under doi:10.1007/s10337-016-3029-9.

Andrés Pérez-Parada

aperez@fq.edu.uy

1 Grupo de Análisis de Compuestos Traza, Departamento de Química Orgánica, Facultad de Química, Universidad de la República (UdelaR), General Flores 2124, 11800 Montevideo, Uruguay

2 Polo Agroalimentario y Agroindustrial, Departamento de Química del Litoral, CENUR Litoral Norte, Universidad de la República (UdelaR), Ruta 3 km 363, Paysandú, Uruguay 